mainly commercial and that our university system was greatly in fault. He was too much overcome by his countrymen's overwhelming success in the industrial field; he did not see that no real attempt had been made by the world to meet their competition. The world, in fact, had been hypnotised by Germany's ordered progress.

Our action after the War was stupid. We allowed lawyers to put themselves in charge. These were followed by so-called business men. We have yet to give technical knowledge and efficiency their due place. This will ultimately be our sole chance of securing our proper share in the world's work. Our recent partial success in re-establishing the dyestuff industry may largely be attributed to the example set by $\mathrm{Mr}$. James Morton, whose acute mind led him to surround himself with a picked band of competent workers and to accept their guidance unreservedly. The outstanding service rendered by his chief assistant, the late Dr. Thomas, has yet to be sufficiently recognised; he was the nearest approach to a Duisberg we have had. We have to take pains that we may breed such men-at present our schools are worthless for the purpose-indeed, they prevent them from arriving. If our industry is to prosper, we must abolish all clerical control of education and put it under men of scientific out. look-men who not only know something but also know how to use knowledge The present ignorance of the schools will never give us this. The future of the dyestuff industry will depend entirely upon the attitude of the public towards colour-upon the development of the colour sense. The present world tendency is to abandon colour-everywhere black prevails : an almost lost sense has to be recovered.

Chemists belong to no nation: the world over they are a community ; one in spirit, in thought and in method, interdependent in their work. Eventually they must lead the world, as they alone can understand its operations. The service Duisberg rendered was to the common good. All can recognise the worth of the man, apart from his nationality ; the value of the great example he set, apart from his technical service, by the exercise of a wide public activity and a wide philanthropy. Only by the aid of such men will the world eventually be sufficiently brought together in har monious interrelationship.

\title{
Quantum Mechanics as a Physical Theory
}

7 HE issue of the Physical Review dated May 15 contains a contribution by Prof. A. Einstein, B. Podolsky and N. Rosen under the title: "Can Quantum - Mechanical Description of Physical Reality be Considered Complete?" The authors answer this question in the negative. They begin by pointing out that it is important to draw a distinction between the physical concepts, which are introduced into a theory and form its subject matter, and the objective reality, which is independent of the theory and which it is the purpose of the theory to describe. That is to say, we have to draw a distinction between the results of experiment and our theoretical description of them.

In order to test a theory the authors ask two questions: (1) Is the theory correct? And (2), Is it complete? The content of the paper is a consideration of the answers obtained when these questions are applied to quantum mechanics.

The first question can be answered in the affirmative if the theoretical conclusions agree with experiment. In physics, we test correctness by means of numerical values, and in this respect the authors have no adverse criticism to make of the quantum theory. The second question is a more difficult one, and some explanation of its meaning is required before an answer can be attempted.
A complete theory is understood to be one which provides a counterpart to each element of physical reality. The definition of physical reality lies at the root of all that follows in the paper. The authors say: If, without in any way disturbing a system, we can predict with certainty the value of a physical quantity, then there exists an element of physical reality corresponding to this physical quantity. They accept this as a reasonable criterion. They do not regard it as a necessary but as a sufficient condition of reality.

Accepting this definition, the authors go on to show that the quantum-mechanical description of physical reality is not complete. The first step in the argument is to show that the uncertainty principle places two alternatives before us. Suppose that two physical quantities are represented in the theory of quantum mechanics by the operators $A$ and $B$. If these operators do not commute, that is, $A B \neq B A$, then the theory maintains that precise knowledge of one quantity is incompatible with precise knowledge of the other. The best known example of this is that in which the physical quantities are the co-ordinate of position and the momentum of an electron. We can only obtain precise knowledge of the second quantity by experiment, and in attempting this we destroy 
our knowledge of the first. But both operators represent objects of physical reality, so that by the definition it must be concluded either that the theory does not contain concepts for both, that is, it is incomplete, or else the two quantities have not physical reality at the same time. In quantum mechanics it is assumed that the wave function contains a complete description of this reality for the state to which it corresponds. This is reasonable, since the information obtainable from this function corresponds exactly to that which can be predicted with certainty without altering the state of the system.

In the final stage of the argument, an appeal is made to the process known as reduction of the wave packet. We must refer to the original paper for the details, but it is deduced that it is possible to predict with certainty two quantities corresponding to physical realities, and moreover that these quantities are represented by non-commuting operators. Thus we have to admit that if the quantum theory is complete and therefore contains concepts for these quantities then, although noncommuting, they correspond simultaneously to physical realities.

We saw that the uncertainty principle presented us with two alternatives; and now we see that if we deny the first of these alternatives, we have also to deny the second. The conclusion is that the first alternative, that the quantum theory is incomplete, has to be accepted.

It is possible that the criticism does not strike at the root of the quantum theory, since so much depends upon a definition of physical reality, which is not of necessity included in the theory. If we could be satisfied that the definition is necessary or that without it two simultaneous conjugate physical quantities are represented by commuting variables, then the quantum theory fails. An interesting letter on this point from Prof. G. Temple appears in Nature of June 8 (p. 957).

The paper by Einstein and his collaborators is rather to be regarded as an appeal for a more direct description of the phenomena of physics. The authors seem to prefer the artists' portrayal of the landscape rather than a conventional representation of its detail by symbols which bear no relation to its form and colour. The expression of a belief that it is possible to provide a complete description of physical reality indicates the nature and purpose of the criticism. Presumably the appeal is for a replacement of the operator calculus of the quantum theory by a method of description which resembles that of the classical and relativistic theories in that, like them, it introduces concepts more directly corresponding to physical realities.

In criticising quantum mechanics in this way, we must remember that it arose out of the inadequacy of existing models, and it has evolved in its particular way because it has had to do without them. The theory has done what, in the face of difficulty, it set out to do. It does not profess to describe actual phenomena but the possible results of measurements, and it is particularly concerned with the influence of the observer on the quantities observed. Much work is being done at present on the notation of the quantum theory. There are difficulties to be removed and with their removal we may find that we have travelled in the direction desired by the three authors. Physicists can scarcely remain content with a situation in which the electron is an equation, and the remark sometimes heard that the school of quantum mechanies is content to establish itself merely as a bureau for ready reckoning is by no means true. H. T. F.

\section{U.S. Stratosphere Balloon Explorer II}

\begin{abstract}
A BRIEF reference was made in NATURE of A February 23, p. 299, to the remarkable preparations afoot in the United States to launch a new attempt in stratosphere research following on the mishap to Explorer I. News has now come to hand that everything was ready by June 1 and the balloonists are only awaiting favourable weather conditions. The outstanding feature of this new experiment is the display of co-ordination of effort on the part of the National Geographic Society, the U.S. Army Air Corps and many of the public bodies interested in research. Capts. A. W. Stevens and O. A. Anderson will again ascend, and Capt. R. P. Williams is in charge of ground operations and has been named as alternative pilot.
\end{abstract}

Some idea of the magnitude of the task can be gained from the following details of the balloon and the experiments.

\section{BALLOON}

This was built and designed by the Goodyear Zeppelin Corporation, Ohio. When inflated it is $192 \mathrm{ft}$. in diameter and has a capacity of $3,700,000$ cub. ft. and an area of $2 \frac{2}{3}$ acres. Its initial charge will be $300,000 \mathrm{cub}$. ft. of helium, and with this 'bubble' of gas in it the top will rise $316 \mathrm{ft}$. from the ground when it is all complete and ready to start. The envelope is made of rubberised fabric, most of it weighing $5 \cdot 3 \mathrm{oz}$. a square yard, at the top $7 \cdot 2 \mathrm{oz}$. a square yard. The gas can be released 